\title{
Professionalism in undergraduate dental education: a pause for thought
}

\author{
Heidi Bateman, ${ }^{* 1}$ Janice Ellis² and Giles McCracken ${ }^{3}$
}

\section{Key points}

Professionalism is a complex phenomena that is difficult to articulate and is easily confused and contested within and between stakeholder groups.
The regulator, the public and the profession as stakeholders in this debate need to take time and give considered thought when working together going forward.
This should support appropriate solutions to the challenges associated with delivering graduates with 'proven' professional attributes.

\begin{abstract}
Professionalism in dental education, as well as in the wider dental profession, is a regularly discussed and debated topic. It may seem obvious what is meant by 'professionalism' and in many situations it is clear what constitutes a professional approach or behaviour, but contention exists in how to articulate, measure and consider aspects of this complex and context dependent phenomenon. Getting 'it' right early on, with our students and new graduates, is a strategic priority, contributing to 'upstream' activities which have an intention of preventing future issues or harm. The aim of this article is to summarise the challenges faced by providers of undergraduate education (and the dental regulator) in the UK in defining and determining attainment of 'professionalism' before registration. It is timely to take an opportunity for pause, re-assess frameworks and consider future direction.
\end{abstract}

\section{Background}

Much has been made in recent literature of the perceived negative shift in 'skills' of the 'dental graduates of today' in comparison with those qualifying in years gone by. ${ }^{1,23}$ This is not a new development; it is interesting to note that articles published in this Journal have discussed the skills shift for at least two decades, with those currently expressing concern being potentially themselves of the generation who were similarly criticised previously.

In an Opinion article published in 1999 entitled 'Are graduates as good as they used to $b e ?, 3$ the authors comment:

${ }^{1}$ Clinical Trainer in Restorative Dentistry/Honorary Clinical Senior Lecturer, School of Dental Sciences, Newcastle University, UK; ${ }^{2}$ Professor of Dental Education/Honorary Consultant in Restorative Dentistry, School of Dental Sciences, Newcastle University, UK; ${ }^{3}$ Professor of Restorative Dentistry/Honorary Consultant in Restorative Dentistry,

School of Dental Sciences, Newcastle University, UK

*Correspondence to: Heidi Bateman

Email: heidi.bateman@newcastle.ac.uk

Refereed Paper.

Accepted 26 September 2019

https://doi.org/10.1038/s41415-019-0991-2
'The graduates of today are different from those of 10 or 20 years ago, but dentistry is changing and those that we are now qualifying face a very different world. The newly qualified are not what they used to be, nor we suggest, should they be. They are different, but that does not mean worse."

The above quote exemplifies the notion that skill shift per se is not of concern if appropriate and enabling graduates to deal with the healthcare needs of modern society (future proofing). In recent years there has undoubtedly been a significant change in the ethos of delivery of dental care with far greater emphasis on prevention. Moreover, the concept of changing needs and approaches is not new; the proponent for 'extension for prevention', Greene Vardiman Black, was reported to have made this prescient statement:

'The day is surely coming and perhaps within the lifetime of you young men before me when we will be engaged in practising preventive rather than reparative dentistry.'

A further element that is evident in this skill shift, is a change in how expectations of professionalism are articulated with no better illustration being the General Dental Council's 'Preparing for practice: Dental team learning outcomes for practice..$^{5}$ This document (like its predecessor 'The first five years' ${ }^{6}$ ) describes the outcomes for which attainment must be demonstrated by dentists at the point of graduation. The four domains of practice contained within it are: clinical; communication; professionalism; management and leadership. Unlike The first five years, Preparing for practice makes overt reference to, and has a focus on, professional attributes. UK regulators of other clinical professions have adopted a similar approach, albeit using differing formats, producing documentation for education providers that have specific sections outlining required educational goals for 'professionalism. ${ }^{7,89}$ However, this attempt at defining and determining attainment of 'professionalism' is hugely problematic for providers of undergraduate education in the UK due to the complexity of the phenomena, which is multi-faceted with overlapping and interlinking component parts. This complexity doesn't lend itself to sit neatly within existing education assessment frameworks. It is timely 
to pause, to re-assess the appropriateness of such educational frameworks and give consideration to future direction.

The GDC has set out its direction of travel within the 2017 document Shifting the balance $^{10}$ and within this seeks to promote the importance of professionalism in decision making for new and existing dentists and DCPs.

Two of the key purposes of the GDC are to promote and maintain public confidence in the professions it regulates and to promote and maintain proper professional standards and conduct. ${ }^{11}$ Under these purposes, the GDC sees its role to reflect public expectations of professionalism within its standards and guidance, where possible reconciling these with the views of dental professionals. As public expectations change over time, this will continue to be an area of focus for the regulator.

Within Shifting the balance and subsequent updates, the GDC has been clear that it will increase its focus on 'upstream' activities those things that happen before the harm or an issue has occurred. Important to this is working with the profession and partners to promote the importance of professionalism as the thing that should guide a dentist or DCP in their decision making. Matters that are referred to the GDC as fitness to practise concerns are often directly linked to an individual's professionalism (or lack of professionalism) in how they approach their practice and interactions with patients and the dental team.

In terms of dental education, the GDC has responsibility for setting the standards and quality assuring those programmes leading to registration. A revised GDC quality assurance process seeks to introduce thematic activities that will highlight areas for improvement across education providers. These have begun with a review of new dentists' preparedness for practice and in future are likely to include a focus on how education providers ensure that those coming into dentistry are suitably equipped for a career in a caring profession. This may lead to a need to strengthen the emphasis on professionalism within the expected learning outcomes. This will then be left for the education providers to determine both how they can robustly demonstrate attainment of professionalism of their students and how they can ensure that those entering a programme are suited to a career in dentistry. As things currently stand, there are no measures for professionalism and suitability for a career within dentistry which are universally agreed and validated, which creates a very real challenge.

\section{Professionalism - it's obvious, isn't it?}

It is possible some readers may feel that 'being a professional' and 'behaving professionally' is obvious and really doesn't warrant further dissection. That opinion has merit, but as with many things in life (and dentistry), the reality, including practical implications, is not that straightforward. Talking with colleagues, many express the opinion that they 'know professionalism when they see it', and that 'unprofessional' behaviour is easy to identify, $\log$ and address. But can this collective interpretation by the profession ever be transformed into an objective tangibly quantified and consistently applied phenomena within a learning environment where the defensibility of decisions made around progression through, and the award of, degrees may be subject to legal challenge?

Despite the change to a more overt form of governance, has anything really changed in terms of the expectations of those training as professionals of the future? What certainly has changed are the expectations of society as a whole toward provision, receipt and regulation of clinical care. Social media is embedded in the daily lives of students, staff, patients and the wider public. The culture across all professional groups, ${ }^{12,13}$ including clinical professions, is shifting ${ }^{14}$ and dentistry is not alone in the respect of increasing litigation.

There is perhaps a perception of the way we have changed in society from 'never mind, these things happen' to 'sorry but that went wrong and you now need to compensate me'. Maybe this is appropriate, and arguably there was a need for a move in this direction, but as always there are multiple perspectives and viewpoints, many of which have at least some elements of merit. The profile of this shifting culture has been further reinforced in that for dentists practising in the UK, confirmation of indemnity is now part of the annual registration process. Student fitness-to-practise documentation and subsequent proceedings are now embedded within learning programmes, and following the Francis report, ${ }^{15}$ the profile and importance placed on raising concerns has been amplified. This, although both essential and integral, together with anecdotes of failure of perceived professionalism, is something that can have unintended consequences ${ }^{16,17}$ - such as possible fear to consider the delivery of certain procedures which may carry greater 'risk'. Moreover, while educational providers at all levels express widespread concern about students' resilience and mental health, there may be additional anxiety/fear generated within the student body around the wider arena of GDC fitness to practise. This is already driving education providers to reconsider their curricula, aiming to facilitate students in developing a robust professional identity to withstand these pressures.

\section{Challenges in determining attainment of professionalism}

There is a significant and ever increasing body of literature highlighting the challenges of addressing the learning, teaching and assessment of 'being a professional' in the training environment. ${ }^{18,19,20,21,22}$ In attempting to 'simplify' professionalism by splitting it up to things that can be assessed in a way that is clear, fair and repeatable in the context of education, do we risk losing the essence of what we 'feel' encompasses professionalism but have difficulty articulating? Does an assessment that has a candidate demonstrating a small piece of professionalism act as a sample to say they can do the entire 'professional thing'? Consequentially, would such an assessment strategy diminish any purpose or legitimacy? Concern has been expressed ${ }^{23}$ that the drive to 'define' professionalism has resulted in a narrowing and simplification of this complex area and it is actually something 'socially constructed in interaction ${ }^{23}$ and cannot be viewed without considering the social, economic and political realities and priorities of each situation. Context is an important consideration when thinking about 'what is professionalism?',23,24 it impacts to such an extent, that the statement 'it depends on' becomes the answer to most scenarios. A specific scenario may change dramatically dependent on context, the surrounding information, the institutional norms and values, other social pressures and influencing factors. For example, the social pressure to act in a certain way has been described as an influencing factor in how students may behave at certain times. ${ }^{22}$ So, in terms of curricula approach, recommendations from the literature suggest: a range of contributory content; account of context; the necessity of looking longitudinally and not just a 'moment in time'; and use of appropriate multi-source assessment and feedback mechanisms. ${ }^{21,25,26}$ 


\section{The 'need' for quantifiable assessment}

Despite the challenges articulated, there remains a 'need' for quantifiable assessment to confirm attainment by students/graduates. Unlike many undergraduate courses, the study of dentistry is subject to external regulation, so has integral assessment requirements to satisfy both university (academic) progression and regulatory requirements in order to demonstrate both 'sufficiency' of a programme and 'attainment' by students. Assessment therefore has multiple purposes, of which two major categories are feedback (including diagnosis of strengths and development needs, reinforcement/motivation for students, feedback to teachers) and standards (including maintaining standards, guide to progression, consideration of 'safety' to practice and provision of data for quality assurance purposes). ${ }^{27}$

Is the current view of professionalism compatible with the educational systems currently in place and requirements? Ultimately, are we really needing to consider the mismatch between a complex phenomenon and how this is expressed in terms of educational goals and requirements? Are true, well-constructed learning outcomes the most appropriate way forward in the 'quantification' of so-called soft skills, or whether, when considering complex phenomena, a re-think in the approach of articulating educational expectations is more appropriate. ${ }^{28,29}$

\section{Where next?}

We would suggest that the essence of what it is to be a professional hasn't changed in our lifetime, but what has changed is the context, assurances and emphasis on assessing, defining and regulating. This brings with it a change in focus that has multiple challenges. Not least of which is that while we can consider the views of the profession itself, the regulator and the public, these may not always align. The GDC sees that professionalism is inextricably linked to public expectations, which may not always be the same as expectations of the profession. This debate is timely in that the GDC has recently undergone a consultation on its quality assurance of education, including its inspection processes, regular thematic reviews of topical issues in dental education and review of learning outcomes. There is currently an overt and welcome willingness of the regulator to take stock and be open to the views of stakeholders as they anticipate and plan the future development of dental education in the UK. We feel it is fundamental, that as part of this 'new world', a collaborative approach including clear partnership of the GDC with providers, and moreover those with expertise in understanding the profound complexities surrounding professionalism, is sustained.

The bringing together of a tripartite collaboration by the General Dental Council (as the regulator of dental education) including Health Education England (as the funder of dental education) and Dental Schools Council (representing providers of dental education) is providing a forum for the future direction of dental education. We feel it is imperative that this group generates the questions to be answered that will advance and strengthen the evidence base around the evaluation of professionalism in dental curricula. Further, the establishment of the UK Council for Dental Teachers of Professionalism, has brought together interested parties who are sharing good practice, supporting resource development and driving innovation around professionalism in dental education. This group, along with the wider community of clinical educators, are well placed to deliver on the ongoing development of this much needed evidence base.

\section{Acknowledgements}

The authors would like to acknowledge the input and insight of Mr Ross Scales, GDC Head of Upstream Regulation, in the preparation of this manuscript.

\section{References}

1. Gilmour A S M, Jones R J, Cowpe J G, Bullock A D. Clinical skills of a new foundation dentist: the expectations of dental foundation education supervisors. Br Dent J 2018; 225: 73.

2. Oxley C J, Dennick R, Batchelor P. The standard of newly qualified dental graduates - foundation trainer perceptions. Br Dent J 2017; 222: 391-395.

3. Cabot $L B$, Radford D R. Are graduates as good as they used to be? Br Dent J 1999; 186: 318-319.

4. Joseph R. The Father of Modern Dentistry - Dr Greene Vardiman Black. J Conserv Dent 2005; 8: 5-6.

5. General Dental Council. Preparing for practice: Dental team learning outcomes for registration (2015 revised edition). London: GDC, 2015. Available online at https:// www.gdc-uk.org/professionals/education (accessed 9 September 2019).

6. General Dental Council. The first five years. 3rd ed (Interim). London: General Dental Council, 2008.

7. General Medical Council. Outcomes for graduates (Tomorrow's Doctors) 2015. Available online at http:// www.gmc-uk.org/education/undergraduate/undergrad_ outcomes.asp (accessed 9 September 2019).

8. General Osteopathic Council. Guidance for Osteopathic Pre-registration Education 2015. Available online at http://www.osteopathy.org.uk/news-and-resources/ document-library/training/guidance-for-osteopathic-preregistration-education/ (accessed 9 September 2019).

9. Nursing and Midwifery Council. Standards for pre-registration nursing education 2010. Available online at https://www.nmc.org.uk/standards/additionalstandards/standards-for-pre-registration-nursingeducation/ (accessed 9 September 2019).

10. General Dental Council. Shifting the balance: a better fairer system of dental regulation 2017. Available online at https://www.gdc-uk.org/about/what-we-do/shiftingthe-balance (accessed 9 September 2019).

11. Government UK. Health and Social Care (Quality and Safety) Act, 2015.

12. Evetts J. New professionalism and new public management: changes, continuities and consequences. Comp Sociol 2009; 8: 247-266.

13. Evetts J. Introduction: trust and professionalism: challenges and occupational changes. Curr Socio/ 2006; 54: $515-531$

14. Bleakley A, Bligh J, Browne J. Medical education for the future: Identity, power and location. Netherlands: Springer, 2011.

15. Francis R. Report of the Mid-Staffordshire NHS Foundation Trust Public Enquiry: Executive Summary London: The Stationery Office; 2013. Available online at https://www.gov.uk/government/publications/reportof-the-mid-staffordshire-nhs-foundation-trust-publicinquiry (accessed 9 September 2019).

16. Ellis J S, Bateman H, Thomason J M, Whitworth J. Concerns about raising concerns. Med Educ 2015; 49: 514-515.

17. Dental Protection survey reveals 9 in 10 dentists fear being sued by patients [updated 14 November 2018]. Available online at https://www.dentalprotection.org/ uk/articles/dental-protection-survey-reveals-9-in-10dentists-fear-being-sued-by-patients (accessed 20 February 2019).

18. Hodges B D, Ginsburg S, Cruess R et al. Assessment of professionalism: Recommendations from the Ottawa 2010 Conference. Med Teach 2011; 33: 354-363.

19. Ginsburg S, Regehr G, Lingard L. Basing the evaluation of professionalism on observable behaviours: a cautionary tale. Acad Med 2004; 79: S1-S4.

20. Cruess R L. Teaching professionalism: theory, principles, and practices. Clin Orthop Relat Res 2006; 449: 177-185.

21. O'Sullivan $H$, van der Mook W, Fewtrell $R$, Wass V. Integrating professionalism into the curriculum: AMEE Guide No. 61. Med Teach 2012; 34: e64-e77.

22. Rees C E, Knight L V. Viewpoint: The Trouble with Assessing Students' Professionalism: Theoretical Insights from Sociocognitive Psychology. Acad Med 2007; 82: $46-50$.

23. Martimianakis M A, Maniate J M, Hodges B D. Sociological interpretations of professionalism. Med Educ 2009; 43: 829-837.

24. van Mook W N, van Luijk SJ, O'Sullivan $\mathrm{H}$ et al. The concepts of professionalism and professional behaviour: conflicts in both definition and learning outcomes. Eur J Intern Med 2009; 20: e85-9.

25. Goldie J. Assessment of professionalism: a consolidation of current thinking. Med Teach 2013; 35: e952-956.

26. Zijlstra-Shaw S, Robinson P, Roberts T. Assessing professionalism within dental education; the need for a definition. Eur J Dent Educ 2012; 16: e128-e136.

27. Reece I, Walker S. Teaching, training and learning: A practical guide. 6th revised ed: Business Education Publishers, 2007.

28. Bateman H, Ellis J, Stewart J, McCracken G. Using learning outcomes in dental education. Br Dent J 2017; 223: 854-857.

29. Bateman H L, McCracken G I, Ellis J S, Stewart J. Delivering to 'that list': the challenges of working with learning outcomes. Br Dent J 2019; 226: 441-446. 